\title{
PENERAPAN UJI T-BERPASANGAN UNTUK MELIHAT PENGARUH PEMBINAAN SISWA DALAM MENGHADAPI PERSIAPAN LOMBA OLIMPIADE MATEMATIKA
}

\section{Paired T-TEST APPLICATION TO SEE THE EFFECT OF COACHING STUDENTS IN DEALING OF MATH OLYMPIC PREPARATION}

\author{
Oleh: \\ Ulfasari Rafflesia, Pepi Novianti, Dian Agustina, dan Idhia Sriliana \\ Fakultas Matematika dan Ilmu Pengetahuan Alam
}

\begin{abstract}
Bengkulu is an active participant in the National Science Olympic competition in junior level. But the achievement of Bengkulu's students is not prominent, especially in the field of Mathematics. Until now Bengkulu has never been quite encouraging achievement in the OSN. Department of Mathematics University of Bengkulu has a human resource that is promising, the competent faculty who can nurture, guide, and prepare students of SMP Negeri 2 Bengkulu to compete in the OSN. Therefore, students of SMP 2 Bengkulu will be coached to understand, analyze and answer the questions, so that they know the math Olympic the strategy and the ways that fast in answering the Olympics questions correctly, so they will be a champion at the provincial and national competition. After coaching is done, it can be concluded that this activity has not been a significant influence. However, development activities that have been implemented are able to provide the knowledge and insight to junior high school students about the material and questions in math Olympic.
\end{abstract}

Keywords: SMP Negeri 2, Math Olympic, paired T-test

\section{PENDAHULUAN}

Olimpiade Matematika Internasional (OMI) tingkat SMA pertama diselenggarakan pada tahun 1959 di Rumania. Indonesia pertama kali mengikuti ajang ini pada tahun 1988, kala itu IMO dilaksanakan di Canberra, Australia. Hingga tahun 2012, prestasi yang diraih Indonesia terlihat dari peringkat yang diraih, yaitu peringkat 35 dari 100 peserta dengan perolehan 2 perak, 3 perunggu, dan 1 honorable mention. Di Indonesia sendiri, ajang ini diselenggarakan serentak dengan perlombaan bidang ilmu lainnya seperti Biologi, Fisika, Kimia, Astronomi dan Astrologi, serta Komputer dan bernama Olimpiade Sains Nasional atau yang disingkat dengan OSN (Dirjen Dikdas, 2012). OSN memiliki tujuan umum untuk meningkatkan mutu pendidikan Matematika dan Sains secara komprehensif melalui penumbuhkembangan budaya belajar, kreativitas dan motivasi meraih prestasi terbaik melalui kompetisi yang sehat serta menjunjung nilai-nilai sportivitas.

Terdapat tiga tingkatan OSN. OSN tingkat SD mempertandingkan bidang Matematika dan IPA. Tingkat SMP dengan bidang Matematika, Fisika, dan Biologi. Serta 
OSN tingkat SMA dengan bidang Matematika, Fisika, Biologi, Kimia, dan Komputer (Farikhin, 2007). Keluaran dari masing-masing tingkatan OSN inilah yang diharapkan menjadi cikal-bakal wakil Indonesia untuk OMI tingkat SMA. Pada tingkat SMP, OSN pertama kali diselenggarakan pada tahun 2003. Di Yogyakarta pada September 2002 telah diadakan kompetisi ini, tetapi kala itu belum bernama OSN. Setiap propinsi mengirimkan wakilnya yang telah terlebih dahulu melewati seleksi tingkat sekolah, seleksi tingkat kota/kabupaten, dan akhirnya lolos seleksi tingkat propinsi untuk mengikuti kompetisi ini. Propinsi Bengkulu juga merupakan peserta aktif dalam kompetisi ini. Namun prestasi yang diperoleh Bengkulu belum menonjol, terutama di bidang Matematika. Sampai sekarang Bengkulu belum pernah mengukir prestasi yang cukup membanggakan dalam OSN.

Sebagaimana tahapan-tahapan seleksi yang ada, seleksi peserta di Propinsi Bengkulu pun dimulai pada tingkat sekolah hingga tingkat propinsi. Selama ini di Propinsi Bengkulu, wakil untuk maju ke ajang OSN didominasi oleh SMP Negeri 1 dan SMP IT. Sekolah Menengah Pertama lainnya, bahkan seperti SMP Negeri 2 Kota Bengkulu yang tercatat sebagai salah satu sekolah menengah yang cukup diminati, cenderung masih dikalahkan oleh kedua sekolah tersebut. Selama 3 tahun terakhir tidak ada wakil untuk maju ke OSN dari SMP Negeri 2, sementara pada tahun sebelumnya ada. Hal ini boleh jadi disebabkan oleh banyak faktor, salah satunya kurang efektif dan efisiennya pembinaan yang dilakukan.

Jurusan Matematika Universitas Bengkulu memiliki sumber daya manusia yang cukup menjanjikan, yaitu tenaga pengajar berkompeten yang dapat membina, membimbing, dan mempersiapkan siswa-siswa SMP Negeri 2 Kota Bengkulu untuk berkompetisi dalam OSN. Dengan begitu, diharapkan SMP Negeri 2 Kota Bengkulu dapat lebih bisa bersaing dan mengambil tempat sebagai wakil kontingen dari Propinsi Bengkulu dalam ajang OSN, dan bukan tidak mungkin di kemudian hari dapat memiliki prestasi yang membanggakan. Melalui kegiatan ini juga tenaga-tenaga pengajar di Jurusan Matematika dapat berperan aktif mengimplementasikan ilmu yang dimiliki untuk melaksanakan Pengabdian Kepada Masyarakat sebagai salah satu Tri Dharma Perguruan Tinggi. Untuk itu penulisan ini bertujuan untuk mengetahui pengaruh kegiatan pembinaan siswa SMP negeri 2 Kota Bengkulu terhadap penguasaan soal olimpiade matematika.

Adapun tujuan dari kegiatan ini adalah melakukan pembinaan kepada siswa-siswi SMP Negeri 2 Kota Bengkulu agar dapat memahami, menganalisis, dan menjawab soalsoal olimpiade matematika. Selain itu diharapkan siswa dapat mengetahui strategi dan cara-cara cepat dalam menjawab soal-soal olimpiade secara tepat, sehingga mendapatkan juara baik di tingkat provinsi maupun nasional.

\section{METODE PENGABDIAN}

Metode pelaksanaan kegiatan ini dilaksanakan dalam beberapa tahap. Berikut tahapan dan rencana kegiatan yang akan dilakukan (Hermanto, 2011; dan Wiworo, 2004): 
a. Pengumpulan materi dan soal olimpiade

Tahap awal kegiatan ini adalah mengumpulkan bahan dan materi yang meliputi empat bidang, yaitu aljabar, geometri, kombinatorika dan teori bilangan. Selain materi dari setiap bidang, pengumpulan soal dan pembahasannya juga akan dilakukan pada tahan ini. Materi serta soal dan pembahasan setiap bidang akan dibentuk menjadi sebuah modul.

b. Penyeleksian siswa berpotensi di bidang matematika

Siswa yang akan dibina terlebih dahulu diseleksi sebanyak 20 orang. Penyeleksian dilakukan di SMP Negeri 2 dengan bantuan pihak sekolah dalam hal ini adalah guru bidang matematika. Hal ini dikarenakan guru yang langsung berinteraksi dengan siswa lebih mengetahui kemampuan dan potensi siswa. Sehingga diharapkan siswa yang akan mengikuti pembinaan adalah putra-putri terbaik di bidang matematika.

c. Pre-test

Pre-test dilakukan untuk melihat seberapa jauh kemampuan siswa dalam mengerjakan kisi-kisi soal Olimpiade Matematika. soal pada pre-test dibuat menyerupai bentuk soal olimpiade tingkat nasional yang diambil dari soal olimpiade tahun sebelumnya.

d. Pemberian materi dan pembahasan soal

Tahapan ini akan dibagi menjadi 4 kegiatan. Setiap kegiatan akan diberikan materi dan dilakukan pembahasan soal masing-masing bidang. Kegiatan ini akan dilakukan setiap dua minggu sekali, sehingga kagiatan pemberian materi dan pembahasan akan dilakukan dalam waktu dua bulan, yaitu Bulan Agustus dan September. Kegiatan ini dimaksudkan agar siswa lebih memahami teori dan konsep dasar masing-masing bidang soal olimpiade serta memahami maksud dari sebuah soal sehingga bisa menjawab soal secara tepat dan benar.

e. Post-test

Untuk mengetahui manfaat dan dampak dari kegiatan pembinaan ini dilakukan post-test dengan metode yang sama dengan pre-test. Diharapkan hasil post-test yang dilakukan oleh siswa mengalami peningkatan dibandingkan hasil pre-test.

f. Uji-T berpasangan

Untuk mengetahui pengaruh dari kegiatan pembinaan ini akan dilakukan pengujian secara statistik dengan menggunakan analisis data berpasangan. Pengujian bertujuan untuk menguji hipotesis bahwa kegiatan pembinaan olimpiade berpengaruh terhadap pengetahuan siswa SMP Negeri 2 Bengkulu.

Pengujian dua rataan dapat dilakukan apabila datanya berpasangan. Dalam tiap pasangan ini, persyaratan kedua perlakuan dikenakan secara acak dalam satuan yang homogen. Perhitungan selang kpercayaan untuk $\mu_{1}-\mu_{2}$ dalam hal ini didasarkan pada peubah acak

$$
T=\frac{\bar{D}-\mu_{D}}{S_{d} \sqrt{n}}
$$


Bila $\bar{D}$ dan $S_{d}$ peubah acak yang menyatakan rataan sampel dan simpangan baku dari selisih pengamatan dalam satuan percobaan. Seperti pada uji-t gabungan, anggapannya ialah bahwa pengamatan dari tiap populasi adalah normal. Permasalahan dua-sampel pada dasarnya disederhanakan menjadi permasalahan satu sampel dengan menggunakan selisih $d_{1}, d_{2}, \ldots, d_{n}$. Jadi hipotesisnya berbentuk

$$
H_{0}: \mu_{D}=d_{0}
$$

Uji statistik hasil perhitungan menjadi

$$
t=\frac{\bar{d}-d_{0}}{s_{d} \sqrt{n}}
$$

Daerah kritis dibuat dengan menggunakan distribusi t dengan derajat kebebasan n-1.

\section{HASIL DAN PEMBAHASAN}

Kegiatan pengabdian ini berupa pembinaan dalam bentuk upaya dan Strategi untuk Meningkatkan Kemampuan dan prestasi Siswa SMP Negeri 2 Kota Bengkulu dalam mengikuti lomba olimpiade bidang matematika. Kegiatan ini bermanfaat bagi siswa untuk menambah wawasan dan pengetahuan pada mata pelajaran matematika yang terkesan menakutkan bagi sebagian besar siswa. Manfaat yang juga dapat dirasakan oleh pihak sekolah adalah dapat membantu kegiatan ekstrakurikuler yang merupakan program pengembangan diri siswa sekolah. dengan pemerintah daerah dalam merencanakan program pendidikan. Selain itu kegiatan ini juga menunjang salah satu progaram pemerintah. Dimana prioritas utama program kerja Gubernur Propinsi Bengkulu adalah memajukan bidang pendidikan, khususnya dalam meningkatkan mutu pendidikan di Propinsi Bengkulu.

Kegiatan ini telah berhasil dilaksanakan dengan tempat pelaksanaan di SMP Negeri 2 yang beralamat di Jl. Cendana No. 1 Kecamatan Ratu Agung Kota Bengkulu. Peserta dari kegiatan ini adalah siswa kelas VIII SMP Negeri 2 Kota Bengkulu yang diseleksi berdasarkan prestasi di kelas dan nilai raport mata pelajaran matematika. Seleksi ini bertujuan untuk mendapatkan peserta yang realtif homogen dalam memiliki kemampuan pemahaman dalam bidang akademik.

Siswa yang dijadikan peserta harus memenuhi syarat memiliki peringkat sepuluh besar di kelas dan nilai rapot mata pelajaran matematika minimal 8. Seleksi dilakukan oleh pihak sekolah, yaitu guru mata pelajaran matematika. Hal ini dilakukan karena guru yang mengasuh mata pelajaran tersebut lebih mengetahui potensi dan perkembangan siswa.

Hari pertama kegiatan dilakukan pre-test dengan jumlah peserta sebanyak 47 orang. Jumlah ini melebihi jumlah siswa yang telah ditentukan karena ada beberapa siswa kelas VII yang berminat untuk mengikuti kegiatan pembinaan ini. Apresiasi siswa terhadap kegiatan pembinaan olimpiade ini memang cukup besar, tapi dengan pertimbangan 
pengetahuan siswa dan waktu pihak sekolah menentukan kegiatan ini hanya diperuntukkan bagi siswa kelas VIII.

Pemberian materi dalam pembinaan ini diawali dengan pengenalan olimpiade matematika baik dari level SMP, SMA dan Perguruan Tinggi dimana penyeleksiaannya mulai dari tingkat sekolah, Kota/Kabupaten dan Provinsi. Kemudian dilanjutkan dengan penjelasan secara umum materi yang termasuk dalam soal olimpiade Matematika. Adapun yang menjadi materi dalam soal Olimpiade matematika adalah Teori Bilangan, Aljabar, Geometri dan Kombinatorika.

Dari hasil kegiatan dan pantauan langsung yang dilakukan oleh tim dapat disimpulkan bahwa pengetahuan siswa SMP Negeri 2 Kota Bengkulu tentang Olimpiade Matematika masih cenderung kurang, baik dari segi bentuk soal dan materi yang dilombakan. Dasar pemantauan ini adalah dari hasil pre-test yang dilakukan di awal kegiatan. Dari 10 soal pilihan ganda yang diberikan, rata-rata siswa hanya bisa mengerjakan 3 sampai 4 soal. Setelah dilakukan pre-test, siswa juga diajak diskusi mengenai soal yang telah mereka kerjakan. Hampir seluruh siswa peserta test baru melihat bentuk soal yang diberikan dan mereka sangat kesulitan dalam menjawab soal yang ada.
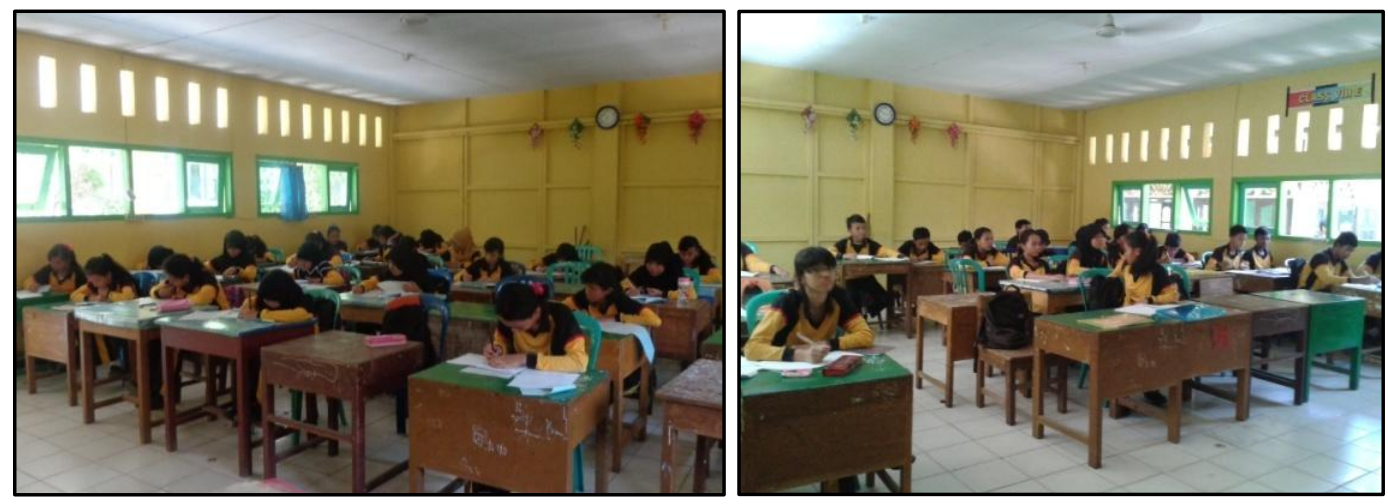

Gambar 1. Suasana pre-test olimpiade matematika SMP Negeri 2 Kota Bangkulu

Waktu yang diberikan untuk mengerjakan 10 soal pilihan ganda adalah 90 menit. Sebagian dari waktu yang diberikan tidak digunakan siswa untuk menyelesaikan soal dikarenakan mereka tidak memahami dan mengetahui cara menjawab soal tersebut dan masih banyak materi yang belum mereka pelajari. Oleh karena itu hampir seluruh siswa menganggap bahwa soal olimpiade itu susah dan membingungkan. Hal ini memang wajar apabila dilihat dari tingkatan kelas dari peserta yang merupakan siswa kelas VIII dan kelas VII. Terutama untuk siswa kelas VII yang merupakan siswa baru di SMP, jadi materi yang mereka terima untuk tingkat SMP masih sangat sedikit. Sedangkan untuk siswa kelas VIII, materi yang diperoleh di tingkat SMP masih sebagian yang dipelajari.

Setelah mengikuti pre-test, sebagian siswa masih tertarik dalam mengikuti pembinaan olimpiade matematika ini. Dari 47 siswa yang mengikuti pre-test masih tersisa 30 siswa yang semuanya merupakan siswa kelas VIII. Pengurangan siswa peserta ini 
diakibatkan oleh pembatasan peserta yang hanya diperuntukan siswa kelas VIII. Pada saat pemberian materi sebagian siswa cenderung susah untuk memahami materi yang diberikan. Sehingga dalam penyampaian materi perlu diberikan penjelasan dan penekanan yang cukup panjang dan memakan waktu. Hal ini dianggap wajar karena soal dalam lomba olimpiade matematika tidak seperti soal dalam materi belajar yang dipwroleh di sekolah. Dalam menjawab soal olimpiade tidak hanya diperlukan rumus dan teori, tetapi juga sangat diperlukan penalaran dan logika yang kuat.

Pertemuan terakhir dari rangkaian kegiatan pembinaan olimpiade ini dilakukan posttest yang betujuan untuk mengevaluasi manfaat dari kegiatan pengabdian pada masyarakat ini. Soal yang diberikan dalam post-test ini masih mengacu pada soal yang diberikan pada saat pre-test dengan pemberian variasi dan beberapa perubahan. Jumlah peserta pada saat post-test ini adalah 20 orang. Dari 20 orang peserta yang mengikuti post-test hanya 16 orang yang juga mengikuti pre-test, sehingga untuk pengujian sampel berpasangan hanya digunakan nilai dari 16 siswa berikut:

Tabel 1. Nilai Pre-Test dan Post-Test Peserta Pembinaan Olimpiade Matematika

\begin{tabular}{lcc}
\hline \multicolumn{1}{c}{ Nama } & Pre-test & Post-test \\
\hline Yehud Hisar Sianturi & 40 & 20 \\
\hline Chandra Sulaiman & 20 & 10 \\
\hline M. Athallah Naufal & 20 & 20 \\
\hline Aknia faza Haryuanti & 40 & 30 \\
\hline Rafidah balqis & 40 & 40 \\
\hline Rahnia Putri & 30 & 20 \\
\hline Ambya Bismiha yanur & 40 & 10 \\
\hline Lamtiur Parsaulina & 20 & 40 \\
\hline Dinda Saprila Veronika & 30 & 40 \\
\hline Fatona hayati Nafsiah & 10 & 40 \\
\hline Nora pika Anggraini & 40 & 30 \\
\hline Vina vaulina & 30 & 30 \\
\hline Nur Asnah & 20 & 20 \\
\hline Shela Putri & 40 & 20 \\
\hline Eka ameva & 40 & 30 \\
\hline Asyifah Dwi Putri & 60 & \\
\hline Sumber: Data hasil & & 50 \\
\hline
\end{tabular}

Sumber: Data hasil observasi, 2013

Nilai rata-rata post-test adalah 28,125 , nilai ini lebih kecil dibandingkan dengan nilai pre-test siswa yaitu 32,5. Namun nilai rata-rata ini secara statistik tidak berbeda. Apabila dilakukan pengujian sampel berpasangan diperoleh nilai t-hitung 1.047 dengan p-value 0.312. karena $p$-value lebih besar dari 5\%, maka dapat disimpulkan bahwa rata-rata nilai pre-test dan post-test tidak berbeda nyata. Hal ini berarti kegiatan pembinaan olimpiade di SMP Negeri 2 belum memberikan pengaruh nyata terhadap penguasaan siswa terhadap 
soal olimpiade matematika. Namun secara keseluruhan kegiatan ini tidak dikatakan gagal, karena dalam waktu 90 menit yang diberikan untuk menyelesaikan soal dapat dikatakan sangat efektif. Hal ini terlihat dari peggunaan waktu dalam menyelesaikan soal, dimana siswa tetap mencoba menyelesaikan dan menjawab soal sampai waktu habis. Bahkan beberapa siswa masih membutuhkan waktu tambahan untuk menyelesaikan soal. Sehingga dapat disimpulkan siswa sudah mulai mengenal dan memahami soal yang diberikan sehingga mereka sudah mulai berusaha untuk mengerjakan dan menyelesaikan dengan benar. Tetapi beberapa faktor mungkin menyebabkan mereka belum dapat menjawab soal dengan baik dan benar, misalanya kurang teliti, terlalu terburu-buru dan merasa berada dalam tekanan.

Tabel 2. Output SPSS untuk Pengujian Dua Sampel Berpasangan

\section{Paired Samples Statistics}

\begin{tabular}{lllrrr}
\hline & \multicolumn{2}{l}{ Mean } & N & \multicolumn{1}{l}{ Std. Deviation } & \multicolumn{2}{l}{ Std. Error Mean } \\
\hline Pair 1 & VAR00005 & 32.5000 & 16 & 12.38278 & 3.09570 \\
\cline { 2 - 6 } & VAR00006 & 28.1250 & 16 & 11.67262 & 2.91815 \\
\hline
\end{tabular}

\section{Paired Samples Test}

\begin{tabular}{|c|c|c|c|c|c|c|c|c|}
\hline & \multicolumn{5}{|c|}{ Paired Differences } & \multirow[b]{3}{*}{$\mathrm{t}$} & \multirow[b]{3}{*}{ df } & \multirow{3}{*}{$\begin{array}{c}\text { Sig. } \\
\text { (2-tailed) }\end{array}$} \\
\hline & \multirow[b]{2}{*}{ Mean } & \multirow{2}{*}{$\begin{array}{c}\text { Std. } \\
\text { Deviation }\end{array}$} & \multirow{2}{*}{$\begin{array}{l}\text { Std. Error } \\
\text { Mean }\end{array}$} & \multicolumn{2}{|c|}{$\begin{array}{l}\text { 95\% Confidence } \\
\text { Interval of the } \\
\text { Difference }\end{array}$} & & & \\
\hline & & & & Lower & Upper & & & \\
\hline Pair 1 pre - post & 4.375 & 16.72075 & 4.18019 & -4.53486 & 13.28486 & 1.047 & 15 & .312 \\
\hline
\end{tabular}

\section{KESIMPULAN DAN SARAN}

\section{Kesimpulan}

Kesimpulan setelah mengadakan kegiatan pengabdian ini adalah kegiatan pembinaan yang telah dilaksanakan mampu memberikan pengetahuan dan wawasan kepada siswa SMP tentang materi dan soal dalam olimpiade matematika. Singkatnya waktu dan pertemuan yang relatif sedikit masih belum cukup untuk memberikan banyak materi dan melakukan pembahasan soal-soal olimpiade kepada siswa kepada siswa. Sebagian peserta pembinaan sangat antusias dan tertarik dalam mengikuti kegiatan pembinaan ini walaupun mereka menganggap soal-soal yang dihadapi relatif sulit. Pihak sekolah sangat mendukung kegiatan pembinaan olimpiade matematika ini, namun karena keterbatasan dana yang dimiliki pihak sekolah untuk melaksanakan kegiatan pembinaan ini maka pihak sekolah tidak berani untuk memperpanjang kegiatan ini dan bekerjasama dengan pihak jurusan matematika FMIPA. 


\section{Saran}

Setelah melaksanakan kegiatan ini, perlu dilakukan kegiatan berkelanjutan yang terus memotivasi, memantau dan mengembangkan pengetahuan siswa dalam menghadapi lomba olimpiade matematika di tingkat kota/kabupaten, provinsi dan nasional.

\section{UCAPAN TERIMA KASIH}

Terima kasih disampaikan kepada Lembaga Pengabdian Pada Masyarakat Universitas Bengkulu yang telah mendanai kegiatan ini melalui DIPA Universitas Bengkulu Nomor: SP-023.04.2.415310/AG/2013.

\section{DAFTAR PUSTAKA}

DIRJEN DIKDAS, 2012, Panduan olimpiade Sains Nasional (OSN) dan Lomba Sains tingkat Internasional Sekolah Menengah Pertama Tahun 2013, Jakarta: KEMENDIKBUD.

Farikhin, 2007, Panduan Olimpiade sains nasional SMP: Mari Berpikir Matematis, Yogyakarta: Graha Ilmu.

Hermanto, E., 2011, Diktat Pembinaan Olimpiade Matematika Materi Dasar, Bengkulu: Tidak Dipublikasikan.

Wiworo, 2004, Metode Pembinaan untuk Menghadapi Olimpiade Matematika SMP (Bagian Pertama), Buletin LIMAS edisi 4. 